Portland State University

PDXScholar

Environmental Science and Management

Faculty Publications and Presentations

2013

\title{
The Value and Propriety of Reintroduction as a Conservation Tool for Rare Plants
}

Edward O. Guerrant Jr.

Portland State University, guerran@pdx.edu

Follow this and additional works at: https://pdxscholar.library.pdx.edu/esm_fac

Part of the Other Environmental Sciences Commons, Plant Sciences Commons, and the Sustainability Commons

Let us know how access to this document benefits you.

\section{Citation Details}

Guerrant, Edward O. Jr., "The Value and Propriety of Reintroduction as a Conservation Tool for Rare Plants" (2013). Environmental Science and Management Faculty Publications and Presentations. 33. https://pdxscholar.library.pdx.edu/esm_fac/33

This Post-Print is brought to you for free and open access. It has been accepted for inclusion in Environmental Science and Management Faculty Publications and Presentations by an authorized administrator of PDXScholar. Please contact us if we can make this document more accessible: pdxscholar@pdx.edu. 


\title{
The Value and Propriety of Reintroduction as a Conservation Tool for Rare Plants
}

\author{
Edward O. Guerrant Jr. \\ The Rae Selling Berry Seed Bank \& Plant Conservation Program \\ Department of Environmental Science and Management \\ Portland State University \\ PO Box 751-ESM \\ Portland, OR 97207 USA \\ ed.guerrant@pdx.edu
}




\section{ABSTRACT}

Three recent reviews of reintroduction for conservation purposes, which draw on substantial and largely non-overlapping data sets, have come to strikingly different conclusions about its value. One concludes that "reintroduction is generally unlikely to be a successful conservation strategy as currently conducted.” Another that "...this review cannot conclusively comment on the effectiveness of re-introductions..." The third concludes there is "strong evidence in support of the notion that reintroduction, especially in combination with ex situ conservation, is a tool that can go a long way toward meeting the needs it was intended to address." The argument over the conservation value of reintroduction is of more than academic interest. It illustrates a challenge facing land managers and decision makers who may be tempted to act on stated conclusions without thoroughly understanding their underlying assumptions, methodology and terminology. The differing conclusions can be partially explained by different criteria of what constitutes success, how to measure it, and differing time scales considered.

The propriety of reintroduction is briefly discussed and focuses on two issues: translocation of naturally occurring individuals to new locations, and introduction outside a species' naturally occurring range. Both have appropriate uses, but can be used in ways that detract from the survival prospects of taxa.

Keywords: reintroduction, introduction, augmentation, ex situ, plant conservation, translocation 


\section{INTRODUCTION}

Reintroduction of rare plants for conservation purposes is an emerging discipline, the value and propriety of which are subject to intense debate. Three recent reviews of reintroduction, drawing on sizeable and largely non-overlapping data sets, have come to starkly different conclusions as to the conservation value of the practice. Godefroid et al. (2011) conclude that "reintroduction is generally unlikely to be a successful conservation strategy as currently conducted." Dalrymple et al. (2011) state “...this review cannot conclusively comment on the effectiveness of reintroductions..." And Guerrant (2012) finds there is "strong evidence in support of the notion that reintroduction, especially in combination with ex situ conservation, is a tool that can go a long way toward meeting the need it was intended to address.": supporting species survival prospects in the wild. In addition, Albrecht and Maschinski (2012) offer an independent analysis of a body of data that shares more taxa in common with Dalrymple et al. $(2011,2012)$, and Guerrant (2012), than with Godefroid et al. (2011). Despite these sharp differences, there is common ground among them.

The debate about the propriety of reintroduction as a conservation tool is made more difficult by the lack of an unambiguous terminology of reintroduction, and also the lack of a consensus metric of success. The debate is further complicated because, although relatively new, rare plant reintroduction in the context of ex situ plant conservation originated at a time when habitat destruction, competition from invasive species, and the prospects of isolated populations inhabiting a permanently fragmented natural world were seen as the overriding threats (Falk 1990). These threats are real and still with us, but in recent years the specter of global climate 
change has begun to loom ever more menacingly. Thus the debate over the propriety of reintroduction, especially of reintroduction outside a species historic or natural range, has become conflated with a growing interest in the notion of assisted migration (aka assisted colonization, managed relocation) as a means of adapting to the biological effects of global climate change.

The contradictory conclusions of the three reviews are explained in part by the authors using different data sets, definitions of success, and time scales. The argument over the conservation value of reintroduction of rare plants illustrates a danger confronting land managers and agency decision makers who may be tempted to act on stated conclusions of any one review without thoroughly understanding the assumptions and terminology that gave rise to those conclusions.

\section{Three disparate views of reintroduction}

Given the high rate of population and species loss, and the potential conservation value of reintroduction, it is perhaps surprising that there had not been a major review of the practice until recently, when three independent reviews were published. Each of them is based on a substantial body of information drawing on a combined literature reviews and surveys: Godefroid et al. (2011), Dalrymple et al. (2011, 2012), and Guerrant (2012) base their conclusions on 172, 123 and 97 taxa respectively. Remarkably, there is relatively little overlap among them: Godefroid shares 12 and 13 taxa with Dalrymple and Guerrant respectively, while Dalrymple and Guerrant have 24 taxa in common. This suggests that there are probably a great many more projects yet to be found, and from which we can all learn. Guerrant et al. (2012) provide a full list of all taxa used by Guerrant (2012), Dalrymple et al. (2012), as well as by Albrecht and Maschinski (2012), 
along with additional information, including references. In addition, information about many taxa and projects can be found online at the Center for Plant Conservation International Reintroduction Registry ( http://www.centerforplantconservation.org/reintroduction/MN_ReintroductionEntrance.asp ). Godefroid et al. (2011) provide a list of taxa and references in supplementary material available online (http://www.sciencedirect.com/science/article/pii/S0006320710004362).

Godefroid et al.'s (2011) bleak opinion of the efficacy of reintroduction follows in part from a gulf between their definition of success and the metric they use to evaluate it. They state (page 674): "Success is defined here as the ability of the population to persist and reproduce. To assess the success of a reintroduction, we focused on the survival, flowering and fruiting rates of the reintroduced plants. Seed production and recruitment are also important metrics for measuring success of a reintroduction, but these data were rarely available in the studies we review here." They go on to assert "...the declining trends in vital rates over the first few years of projects strengthens the conclusion that reintroduction is generally unlikely to be a successful strategy as currently conducted." That their statistical analyses are based on varied and often small subsets of data, generally covering four or fewer years of data, exacerbates problems arising from the disconnect between their definition of success and metric they used to measure it. These factors further complicate critical analysis of the reasoning leading to their conclusions. Nevertheless, they identified a series of shortcomings in study designs common to many projects, and offer a variety of suggestions about how reintroductions might be done better. Many reinforce existing guidelines (Center for Plant Conservation 1991; Australian Network for Plant Conservation Translocation Working Group 1997; Vallee et al. 2004; Maschinski et al. 2012), suggesting that many of the practitioners in their sample may not have been aware of or referred to those 
guidelines.

Dalrymple et al. (2011) state that their “...review cannot conclusively comment on the effectiveness of re-introductions..." This appears due largely to a high proportion of projects for which the fates were unknown at the time of writing. This is not to dismiss what is a very substantial contribution, but merely reflects inherent limitations of the data available for their thorough and robust statistical analytical approach. Despite their modest summary judgment, they were able to glean many important insights into how reintroduction is being practiced and provide a number of valuable suggestions for improvement.

Godefroid et al. (2011), Dalrymple et al. (2011, 2012) and Guerrant (2012) share a number of findings in common. These include an apparent bias in the published literature favoring successful over failed projects. Beyond the common human impulse to favor good news over bad, another factor contributing to a potential bias is the relatively short period of time over which monitoring data are available. The first in a series of perceived weaknesses identified by Godefroid et al. (2011) in how reintroduction is being done is "Insufficient monitoring following reintroduction (usually ceasing after 4 years)". Dalrymple et al. (2011) report "the average monitoring time prior to publishing the outcome of a study is about 3 years." The English language has become the dominant language of both international diplomacy and science, in part because it allows for fine gradations of meaning and exquisite precision. These properties can also be liabilities to effective communication. Note the subtle difference in the way each group reports the approximate duration of monitoring data available. Godefroid et al. (2011) appear to suggest that monitoring is typically done for four years at which time monitoring efforts cease. Dalrymple et al. (2011) are clearly agnostic with respect to whether projects were monitored or 
not after publication. The basis of their cautious conclusion is their explicit distinction between whether they knew the fate of projects in 2009 to be extant, dead, or, as in most cases, unknown.

Guerrant (2012) finds that “...as this volume shows, reintroduction is a solution that works, at least in some circumstances and in some cases." "Plant Reintroduction in a Changing Climate: Promises and Perils" by Maschinski and Haskins (2012) is the fourth book in a series from the Center for Plant Conservation's effort to advance the science and practice of ex situ plant Conservation (Falk and Holsinger 1991; Falk, et al. 1996; Guerrant, et al. 2004). It seeks to review what we have learned over the last couple of decades of conducting reintroductions, and how to use this to advance the science and improve the practice.

In a response to Godefroid et al. (2011), Albrecht et al. (2011) question the value of short term survivorship data of founding individuals as a reliable measure of reintroduction success, contending that initial decline in survivorship after outplanting is to be expected. Indeed, the likelihood of an initial decline in founding population size after planting, which can be thought of as the demographic cost of reintroduction, is sufficiently widespread and substantial to warrant explicit consideration when collecting seed for ex situ storage, or planning a reintroduction (Guerrant et al. 2004; Guerrant and Fiedler 2004). Albrecht et al. (2011) base their criticism on empirical data (see Albrecht and Maschinski 2012; Dalrymple et al. 2011, 2012; and, Guerrant 2012) and simulation modeling results (Guerrant and Fielder 2004). The demographic cost of reintroduction is illustrated in Figure 1, which is adapted from Guerrant and Fiedler (2004; Figure 17.4) onto which are added empirical data from a reintroduction project in Oregon involving the endangered Lilium occidentale Purdy (Guerrant 2001, and unpublished data). It shows the results of stochastic simulation modeling of the projected course of population 
size decline and later growth of six taxa based on empirical data from stage based transition matrix models of demographic studies of populations, all of which have a value of lambda greater than one. In other words, the underlying dynamics of the populations modeled were of growing and not declining populations. The taxa and empirical demographic data on which the stochastic simulations are based are: Astrocaryum mexicanum Liebm. ex Mart., Arecaceae (Piñero et al. 1984); Calathea ovandensis Matuda, Marantaceae (Horvitz and Schemske 1995); Calochortus howellii S. Watson, Liliaceae (Fiedler et al. 1998); Erythronium elegans P.C.Hammond \& K.L.Chambers, Liliaceae (Guerrant 1999); Fumana procumbens (Dunal) Gren. \& Godr., Cistaceae (Bengtsson 1993); Panax quinquefolius L., Araliaceae (Nantel et al. 1996). Each taxon is modeled as a population starting with 1,000 individuals of the smallest stage class described in each study, and the results show mean values of 1,000 stochastic trials. In order to have a single time scale for purposes of comparison between the various simulations and one empirical example, the abscissa was arbitrarily started at year zero.

The take home message of this is that low early survival rates of founding populations is not a reliable indicator of impending failure. Indeed, the surviving populations of Panax quinquefolius modeled, which had an annual mean annual growth rate of 4.5 percent when at a stable stage distribution, declined to a mean size of just 15 individuals out of 1,000 after only three years before beginning to grow. The reference to early years is of course relative, and depends on life history and environmental conditions in which a reintroduction is done. For example, the estimated age at first reproduction was 31 years in the palm, Astrocaryum mexicanum (Guerrant and Fiedler 2004), and 16 in the herbaceous perennial geophyte, Calochortus howellii. 
Unlike the other taxa, Lilium occidentale data in Figure 1 represent a single empirical example and not the results of a simulation model. Note that the number of plants produced by seeds is greater the second year after reintroduction than after the first. The difference being more dramatic in new (collected the year they were planted) than old (having been dried and stored frozen for one to two years) seeds. If we only looked at the results after one year, it would seem that stored seed germinate at twice the rate as new. The point being that initial results may not be broadly predictive of later performance.

In contrast to Godefroid et al. (2011), Dalrymple et al.'s (2011) caution in taking a strong a stand on whether reintroduction is an effective conservation tool is based in large part on the high proportion of reintroduction projects for which the status in 2009 was not known (Figure 2). Compared with the results of Guerrant (2001, plus unpublished data gathered in 2012), the proportion of reintroduction attempts that are known to have had failed (i.e. no reintroduced plants or descendants surviving) are roughly similar for projects five ( 9 vs 5 percent) and ten (13 vs 11 percent respectively) years after planting. The relative proportions of projects either known to be extant in 2009 or whose status in 2009 is unknown are strikingly different. While Dalrymple et al. $(2011,2012)$ report that the proportion of projects at five and ten years whose status is unknown are 75 and 78 percent respectively, Guerrant's figures are much lower (11 and 14 percent respectively.) Projects known to be extant five or ten years after planting show roughly mirror image figures, with the ratio of extant to status unknown after five and ten years is 8.0 and 5.2 versus 0.2 and 0.1 for Guerrant and Dalrymple respectively. Consequently, Guerrant has a greater ability to draw stronger conclusions regarding levels of survivorship than do Dalrymple et al. $(2011,2012)$. The difference is due in part to Guerrant having more recent 
data on projects for which the fate in 2009 was unknown when Guerrant (2012) was written.

In using survivorship rate of founders as their measure of reintroduction success, Godefroid et al. (2011) noted that while seed production and recruitment are also important metrics for measuring success of a reintroduction, such data were rarely available in the studies they review. In contrast, Guerrant was able to obtain data on the reproductive status of founders, production of a next generation, and reproductive status of individuals from the next generation on many projects. Figure 3 summarizes basic information about a total of eighty projects for which some monitoring data were available to Guerrant (2012) in 2009, along with additional information gathered in winter and spring 2012. Of those eighty projects planted between 1986 and 2008, 56 (70\%) had reached sexual maturity by the end of 2009, 28 (35\%) produced a second generation, and in $16(20 \%)$ the second generation had reached sexual maturity.

In terms of survivorship, the fates in 2009 were known for 48 (60\%), of which 45 (56\%) were still extant, and $3(4 \%)$ were known to have failed in that all founders and their descendants were dead. Of the projects for which fate was not known in 2009, subsequent information has been obtained for 26 of 32 projects $(81 \%)$, of which 24 when last seen were alive. One of the two that had died had lived for a total of more than nine years before it and its descendants all died. Overall, 64 of the 80 projects had been planted four or more years before the end of 2009, of which three died before the fourth year, and the fates of another four are unknown. The remaining 57 (89\%) have been monitored for more than four years, and at least five for twenty or more years. Clearly, five projects $(6 \%)$ have failed in that all founders and any and all descendants have died, though one survived for over sixteen years before failing. But can we say the remaining $75(94 \%)$ have succeeded biologically? 


\section{What is success, and how best to measure it?}

Reintroduction success is typically referred to as a summary conclusion for a point in time. Pavlik (1996) makes a useful distinction between biological and project success, and this discussion will refer only to the former. Success in reintroduction has been defined in various ways often with reference to some particular result or series of thresholds, which once attained indicate success. This has the implicit effect of turning reintroduction outcomes into a categorical variable having one two states: success or failure. At one extreme, when all founder individuals and their descendants have died, then a reintroduction has clearly failed biologically. The alternative state, when not all founders or their descendants are dead includes a vast array of possibilities. While failure in reintroduction is an irreversible outcome, success is not.

Among the limitations of viewing success as an end state is that there is an understandable tendency for authors to label project outcomes when they are first reported in the literature, generally only three or four years after planting (Dalrymple et al. 2011, Godefroid et al. 2011). In a useful conceptual step forward, Pavlik (1996) also placed the discussion of reintroduction success in a multifactorial framework, which incorporates various measures of success in four general areas, each of which has multiple components: abundance, extent, resilience and persistence. Rather than referring to success or failure, per se, Guerrant and Kaye (2007) described the outcomes a series of reintroduction projects by noting whether or not they had attained various demographic mileposts such as initial establishment, reproductive maturity, the production of a next generation, and whether or not any founders or their descendants were extant. If still extant at the time reported, for how long they had survived, and if not, for how 
long they survived.

Overall, success may best be viewed not as a summary conclusion, or final result, but in terms of progress or status reports at one or more times after outplanting. There is a need for reintroduction practitioners and the ex situ plant conservation community more generally to develop consensus on what constitutes a minimally necessary and sufficient set of baseline descriptors to characterize the progress of a reintroduction, ideally linked to a more comprehensive set of data, and make all of it available in a web based database.

\section{Terminology and Propriety}

Issues of propriety of reintroduction are necessarily linked to the terminology of reintroduction. Although there are a number of sets of definitions in the literature, none has emerged as a consensus standard. Dalrymple et al. (2011) provide a useful summary of the terminological challenges we face, one example from which is used here to illustrate the implications for discussions of the propriety of reintroduction.

Dalrymple et al. (2011) note that in the USA, translocation is used to mean the movement of extant, naturally occurring plants to new locations, whereas in the UK and Australia translocation is the most inclusive, general term for what in the USA is referred to as reintroduction. But in the USA, reintroduction is used both as the most inclusive general term, as well as less inclusively to mean placing a taxon back within a portion of its historic range, or even more narrowly to restoring genetic material to the specific location from which it has 
become extirpated.

A thorough discussion of propriety is beyond the scope of this piece, but there are two particularly problematic areas: the removal of naturally occurring individuals to other locations, and attempts to establish populations outside their naturally occurring range. The first will be referred to here as translocation in the USA sense of the term, and the second as introduction outside a species' naturally occurring range. Neither practice is categorically inappropriate. But each and every potential use of either must be evaluated in context to ensure it does not constitute a threat to the taxon's long term survival prospects.

Translocation can be an ethically acceptable tool if it is clear that a population's habitat is going to be destroyed and that nothing can be done to prevent it. There is a broad consensus that translocation for the purpose of facilitating a change in land use, and thus destroying suitable habitat is ethically inappropriate. Between these extremes is an ethical gray area, where, for example, how even entertaining the possibility of translocation may directly or indirectly influence the decision to allow habitat to be destroyed. Reintroduction is at best an imperfect tool, but it can and must be done in ways that do not endanger the source population, for example, by removing seeds instead of plant parts or worse, whole plants (Menges 1998; Menges et al. 2004).

Introduction outside a species' naturally occurring range can be a valuable tool where only a single population is known to exist and a second or more are established (Currin et al. 2007; Currin and Meinke 2008), or the existing range has or will soon be rendered unsuitable for habitation. In Western Australia, Monks and colleagues introduced at least three species of 
Proteaceae outside their historic ranges in order to find habitat free of the exotic pathogenic agent of dieback disease (Phytophthora cinnamomi Ronds) (see Guerrant, 2012). Introduction of species outside their historic ranges had its own ethical challenges even before it became conflated with notions of assisted migration or managed relocation as a way to confront the effects of global climate change. Haskins and Keel (2012) and Reichard et al. (2012) provide excellent overviews of issues having to do with managed relocation.

\section{CONCLUSIONS}

The starkly contrasting conclusions of three recent reviews of reintroduction for conservation purposes can be explained in part by differences in their apparent assumptions, methods, and criteria for defining and recognizing success or failure. The data sets of the particular taxa and projects analyzed by each differ as well. Guerrant (2012) has the most optimistic view of the three, which contrasts more strongly with Godefroid et al (2011) than it does with Dalrymple et al. $(2011,2012)$.

An example of a large difference in apparent assumptions is that Dalrymple et al. $(2011,2012)$ are explicitly agnostic with respect to whether and how long projects may or may not be monitored after outplanting based on reported monitoring times. In contrast, Godefroid et al (2011) appear to assume that monitoring ceased with the duration reported. The differences themselves between the duration of monitoring reported by each are small, three and four years respectively, but the implications between them are great. Where Dalrymple et al $(2011,2012)$ acknowledge considerable uncertainty in their results with respect to how long projects are 
ultimately monitored, Godefroid et al (2011) appear to suggest that monitoring was done only for the time period they report. In contrast, Guerrant found monitoring lasted more than four years in almost $90 \%$ of the sample of projects he reviewed that were four or more years old in 2009 , and some have been monitored for over two decades.

Godefroid et al. (2011; pg 679) assert that "These data suggest that most plant reintroductions will not be successful over the long-germ." Their dire conclusion follows from a disconnect between their definition of success - the ability of a population to persist and reproduce - and the metric they used to measure success: survival, flowering, and fruiting rates of reintroduced plants. Albrecht et al. (2011) argue that short term vital rates of the individuals in the founding population, in terms of survival and/or reproduction, are not necessarily reliable indicators of long term success or failure, because initial declines in the founding population are to be expected. Their argument is based on empirical data and results of simulation studies which are themselves rooted in empirical data.

Given that failure is permanent while success is not, reintroduction is like Yogi Berra's view of a baseball game: "it ain't over 'til it's over." Rather than seek to define success as a static end state or conclusion, we may do better to develop one or more multivariate standards, perhaps based on Pavlik's (1996) four goals of abundance, extent, resilience, and persistence, by which the progress of reintroduction projects can be described, evaluated, and compared. 


\section{ACKNOWLEDGEMENTS}

Many people have contributed to the development of this paper, directly and indirectly. Much of the groundwork was put in place as part of the effort to organize the Center for Plant Conservation symposium that culminated in the publication of Maschinski and Haskins (2012). I

thank Sarah Reichard, Wendy Gibble, Julie Combs and everyone else who organized the symposium from which this publication is based: Conserving Plant Biodiversity in a Changing World: A View from NW North America, March 13-14, 2012, at the University of Washington Botanic Gardens, Seattle, WA. This paper benefited from discussions with Joyce Maschinski, Matthew Albrecht and Sarah Dalrymple, and the latter two provided critical commentary on the manuscript, all of which improved the final product. Two anonymous reviewers provided constructive critical commentary for which I thank them. 


\section{LITERATURE CITED}

Albrecht, M.A., Guerrant, E.O. Jr., and Maschinski, J., and Kennedy, K. 2011. A long-term view of rare plant reintroduction. Biological Conservation. 144 (11): 2557-2558.

Albrecht, M.A., and Maschinski, J. 2012. Influence of founder population size, propagule stages, and life history on the survival of reintroduced plant populations. In Plant reintroduction in a changing climate: Promises and Perils. Edited by J. Maschinski and K.E. Haskins.Island Press, Washington, D.C.: $171-188$.

Australian Network for Plant Conservation Translocation Working Group. 1997. Guidelines for the translocation of threatened plants in Australia. Canberra, Australian Network for Plant Conservation. $80 \mathrm{p}$.

Bengtsson, K. 1993. Fumana Procumbens on Oland--Population dynamics of a disjunct species at the northern limit of its range. Journal of Ecology 81(4): 745-758.

Center for Plant Conservation. 1991. Genetic sampling guidelines for conservation collections of endangered plants. In Genetics and Conservation of Rare Plants. Edited by D.A. Falk and K.E. Holsinger. Oxford University Press, New York: 225 - 238.

Currin, R. and Meinke, R.J. 2008. Malheur wirelettuce (Stephanomeria malheurensis) reintroduction and seed bulking: 2008 recovery efforts, Report prepared for U.S. Fish and 
Wildlife Service, Region 1, Portland, Oregon. Oregon Department of Agriculture, Salem, Oregon. 46 p.

Currin, R., Meinke, R.J., and Raven, A. 2007. 2007 Malheur wirelettuce (Stephanomeria malheurensis) recovery efforts: reintroduction and seed bulking, Prepared by Oregon Dept. of Agriculture and Berry Botanic Garden for US Fish and Wildlife Service, Region 1. 69. p.

Dalrymple, S.A., Banks, E., Stewart, G.B., and Pullin, A.S. 2012. A meta-analysis of threatened plant reintroductions from across the globe. In Plant Reintroduction in a Changing Climate: Promises and Perils. Edited by J. Maschinski and E. H. Haskins. Island Press, Washington, D.C.: pp. $31-50$.

Dalrymple, S.A., Stewart, G.B., and Pullin, A.S. 2011. Are reintroductions an effective way of mitigating against plant extinctions? CEE review 07-008 (SR 32), Collaboration for Environmental Evidence. $63 \mathrm{p}$.

(http://www.environmentalevidence.org/Documents/Completed_Reviews/SR32.pdf)

Falk, D.A. 1990. Integrated strategies for conserving plant genetic diversity. Annals of the Missouri Botanical Garden 77(1): 38-47.

Falk, D.A., and Holsinger, K.E. Editors 1991. Genetics and conservation of rare plants. Oxford University Press, New York. 283 p. 
Falk, D.A., Millar C.I., and Olwell, M. 1996. Guidelines for developing a rare plant reintroduction plan. In Restoring Diversity: Strategies for Reintroduction of Endangered Plants. Edited by D.A. Falk, C.I. Milar and P. Olwell. Island Press, Washington, D.C. pp. 453 - 490.

Fiedler, P.L., Knapp, B.E., and Fredricks, N. 1998. Rare plant demography: Mariposa lilies (Calochortus: Liliaceae). In Conservation Biology: For the Coming Decade. Edited by P.L. Fiedler and P.M. Kareiva. Chapman \& Hall, New York: pp. 28 - 48.

Godefroid, S., Piazza, C., Rossi, G., Buord, S., Stevens, A.D.; Aguraiuja, R., Cowell, C., Weekley, C. W., Vogg, G., Iriondo, J.M., Johnson, I., Dixon, B., Gordon, D., Magnanon, S., Valentin, B., Bjureke, K., Koopman, R., Vicens, M., Virevaire, M., Vanderborght, T. 2011. How successful are plant species reintroductions? Biological Conservation 144(2): 672-682.

Guerrant, E.O. Jr. 1999. Comparative demography of Erythronium elegans in two populations: one thought to be in decline (Lost Prairie), and one presumably healthy (Mt. Hebo). Final report on five transitions, or six years of data. Unpublished technical report prepared for the USDI Bureau of Land Management, and USDA Forest Service. 85 p.

Guerrant, E.O. Jr. 2001. Experimental reintroduction of the endangered western lily (Lilium occidentale). Conservation of Washington's rare plants and ecosystems. Washington Native Plant Society. Seattle. pp. 201-211. 
Guerrant, E.O. Jr. 2012. Characterizing two decades of rare plant reintroductions. In Plant Reintroduction in a Changing Climate: Promises and Perils. Edited by J. Maschinski, and K.E. Haskins. Island Press, Washington, D.C.: pp. 9 - 29.

Guerrant, E.O. Jr, Albrecht, M.A., and Dalrymple, S. 2012. Studies used for meta-analyses. Appendix 2. In Plant Reintroduction in a Changing Climate: Promises and Perils. Edited by J. Maschinski, and K.E. Haskins. Island Press, Washington, D.C.: pp. 307 - 317.

Guerrant, E.O. Jr., and Fiedler, P.L. 2004. Accounting for sample decline during ex situ storage and reintroduction. In Ex Situ Plant Conservation: Supporting Species Survival in the Wild. Edited by E.O. Guerrant Jr., K. Havens, and M. Maunder. Island Press, Washington, D.C.: pp. $365-385$.

Guerrant, E.O. Jr., Fiedler P.L., Havens, K., Maunder, M. 2004. Revised genetic sampling guidelines for conservation collections of rare and endangered plants. In Ex Situ Plant Conservation: Supporting Species Survival in the Wild. Edited by E.O. Guerrant Jr., K. Havens, and M. Maunder. Island Press, Washington, D.C.: pp. 419 - 441.

Guerrant, E.O., Jr., Havens, K., Maunder, M. Editors. 2004. Ex Situ Plant Conservation: Supporting Species Survival in the Wild. Island Press, Washington D.C.. 504 p.

Guerrant, E.O., Jr. and T. Kaye. 2007. Reintroduction of rare and endangered plants: Common factors, questions and approaches. Australian Journal of Botany 55: 362-370. 
Haskins, E.H. and Keel, B.G. 2012. Managed Relocation: Panacea or Pandemonium? In Plant Reintroduction in a Changing Climate. Edited by J. Maschinski and E.H. Haskins. Island Press, Washington, D.C.: 229-241.

Horvitz, C.C. and Schemske, D.W. 1995. Spatiotemporal variation in demographic transitions of a tropical understory herb: Projection matrix analysis. Ecological Monographs 65(2): 155-192.

Maschinski, J., Albrecht, M.A., Monks, L.T., Haskins, K.E. 2012. Center for Plant Conservation best reintroduction practice guidelines. In Plant Reintroduction in a Changing Climate: Promises and Perils. Edited by J. Maschinski and E.H. Haskins. Island Press, Washington, D.C. : pp. 277306.

Maschinski, J., Haskins, K.E. Editors. 2012. Plant Reintroduction in a Changing Climate: Promises and Perils. Island Press, Washington, D.C.: 401 p.

Menges, E. S. 1998. Evaluating extinction risks in plant populations. In Conservation Biology: For the Coming Decade. Edited by P.L. Fiedler and P.M Kareiva, Chapman \& Hall, New York: pp. $49-65$.

Menges, E.S., Guerrant, E.O. Jr., and Hamzé, S. 2004. Effects of seed collection on the extinction risk of perennial plants. In Ex Situ Plant Conservation: Supporting Species Survival in the Wild. Edited by E. O. Guerrant, Jr., K. Havens and M. Maunder. Island Press, Washington, 
D.C.: pp. $305-324$.

Nantel, P., Gagnon, D., and Nault, A. 1996. Population viability analysis of American ginseng and wild leek harvested in stochastic environments. Conservation Biology 10(2): 608-621.

Pavlik, B. M. 1996. Defining and measuring success. In Restoring diversity: Strategies for the reintroduction of endangered species. Edited by D. A. Falk, C. I. Millar and M. Olwell. Island Press, Washington, D.C.: 127-156.

Piñero, D., Martinez-Ramos, M., and Sarukhán, J. 1984. A Population model of Astrocaryum mexicanum and a sensitivity analysis of its finite rate of increase. Journal of Ecology 72 (3): 977 $-991$.

Reichard, S.H., Liu, H., Husby, C. 2012. Is managed relocation of rare plants another pathway for biological invasions? In Plant Reintroduction in a Changing Climate: Promises and Perils. Edited by J. Maschinski and E.H. Haskins. Island Press, Washington, D.C.: pp. 243-261

Vallee, L., Hogbin, T., Monks, L. T., Matthes, M., Rossetto, M. 2004. Guidelines for the translocation of threatened plants in Australia. Second Edition. Australian Network for Plant Conservation, Canberra: 80 p. 
Figure 1. Stochastic modeling results for six taxa based on empirical demographic studies all with populations projected to be growing (i.e. lambda $>1$ ), based on Figure 17.4 in Guerrant and Fiedler (2004), onto which empirical results for reintroduction of Lilium occidentale, showing the course of survivorship of three propagule types, new seeds, old seeds, and yearling bulbs.

Figure 2. Histograms showing relative proportions of reintroduction projects whose status is known to be dead, extant, or unknown 5 and 10 years after planting. Data from Dalrymple (2012) and Guerrant (2012, and unpublished data)

Figure 3. Graphical summary of 80 reintroduction projects in order of planting, based on Figure 2.1 in Guerrant (2012). Vertical lines with no marker at the top indicate when a reintroduction was last seen, and was alive. Horizontal dashes indicate the last known time a reintroduction known to have failed was still alive. Information about most projects ends just before the 2010 and represents our knowledge of these projects at the time of the Center for Plant Conservation symposium for which the data were originally gathered. An effort was made in the early months of 2012 to ascertain the fates of projects for which the fate in 2009 was unknown to me, and the results of these inquiries are placed after short spaces in some vertical lines. Some of these extend beyond 2010, others do not. No attempt was made to follow up on those projects whose fate in 2009 was known. Triangles at top of each column indicate that at least one individual has reached reproductive status, a circle, that a next generation has been produced, and a square if next generation has reached reproductive maturity. See Guerrant (2012) and Guerrant et al. (2012) for list of taxa and references. Dashed lines indicate five year iso-chronoclines beginning 
with January 1, 1990, before which only four projects had been planted, the first in 1986, and ending with the top dashed line indicating January 1, 2010. 


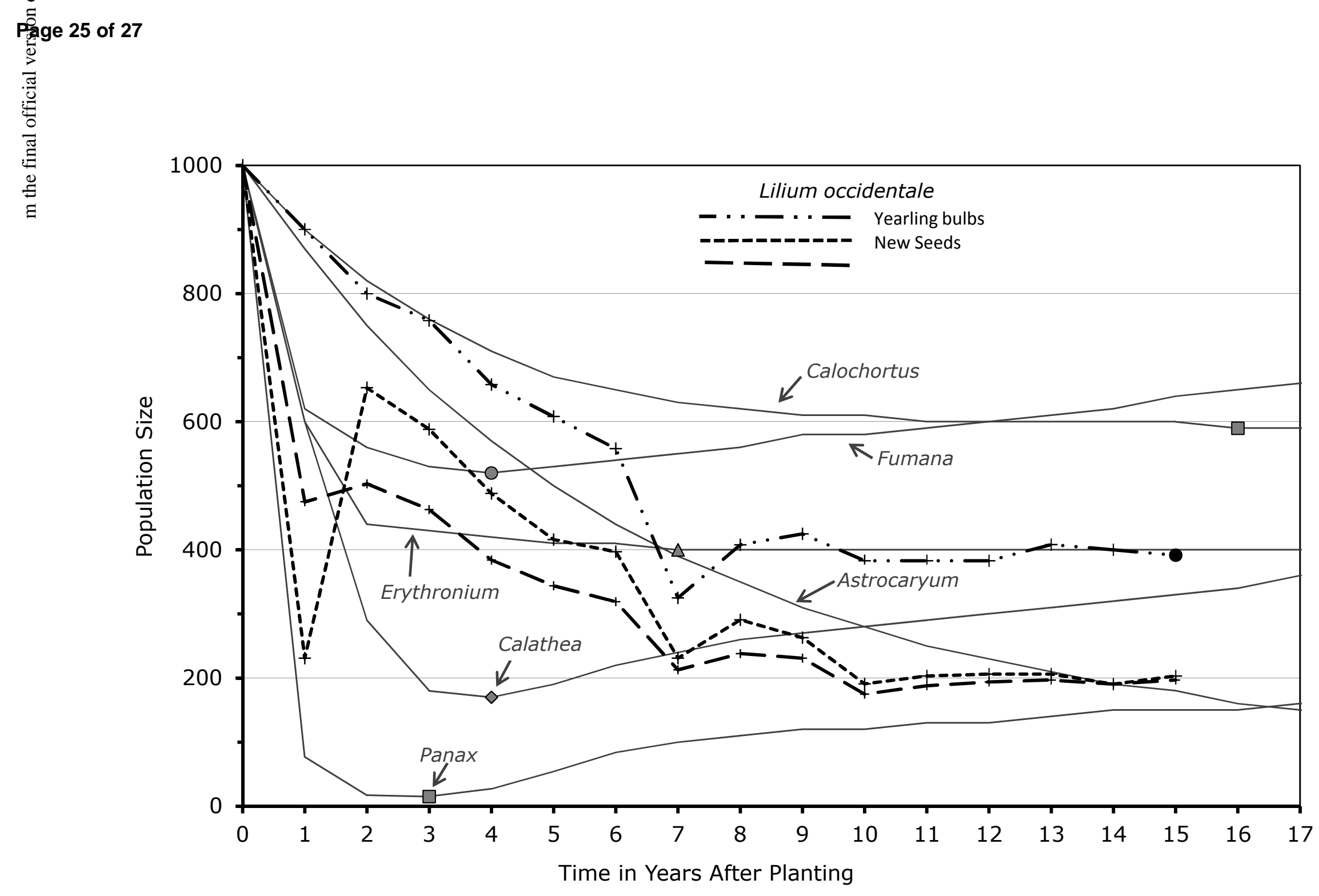




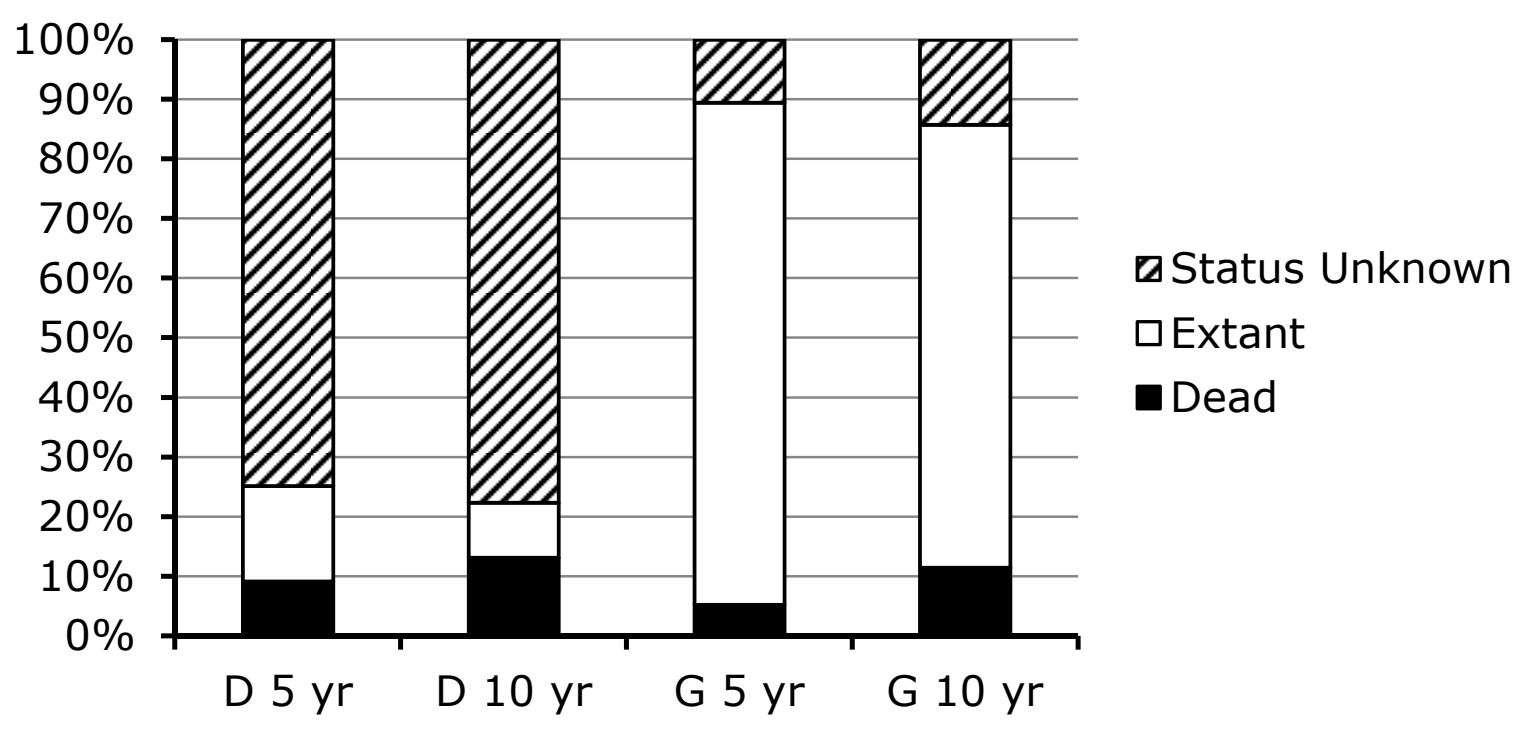




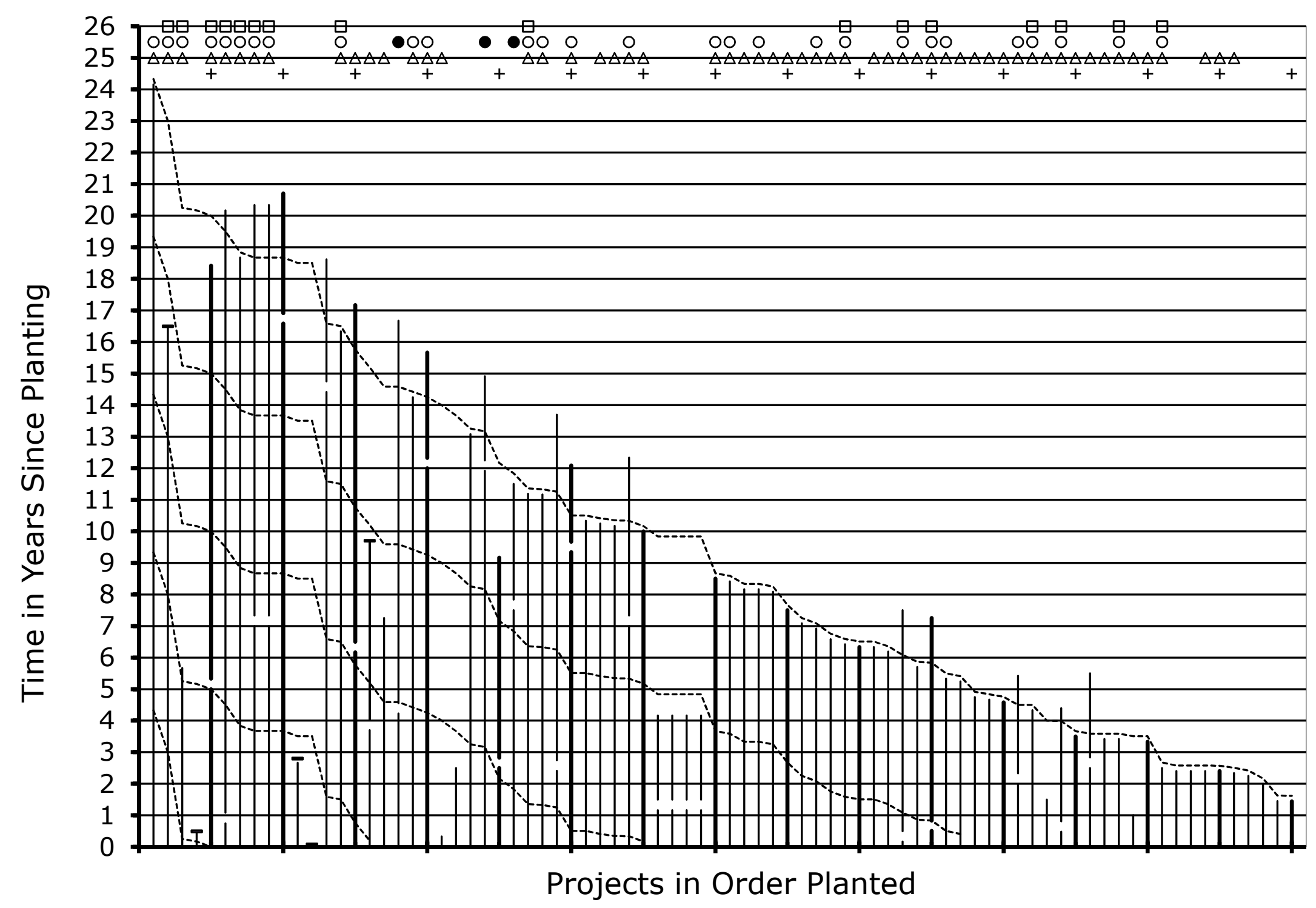

